\title{
Correction to: Proposal for a simple algorithm to differentiate adult-onset Still's disease with other fever of unknown origin causes: a longitudinal prospective study
}

\author{
Emre Bilgin ${ }^{1}$ - Mutlu Hayran ${ }^{2}$ - Abdulsamet Erden ${ }^{1}$ • Berkan Armağan ${ }^{1}$ - Alper Sarı ${ }^{1}$ • Levent Kılıç ${ }^{1}$. Ali Akdoğan ${ }^{1}$. \\ Ömer Karadağ ${ }^{1}$. Şule Apraş Bilgen ${ }^{1}$. Sedat Kiraz ${ }^{1}$ • İhsan Ertenli ${ }^{1}$ • Umut Kalyoncu ${ }^{1}$
}

Published online: 19 February 2019

(C) International League of Associations for Rheumatology (ILAR) 2019

\section{Correction to: Clinical Rheumatology \\ https://doi.org/10.1007/s10067-019-04455-y}

The author regrets that the original version of this article contained error. Figure 1 was shown in the wrong version, thus corrected figure is shown in this article.

The online version of the original article can be found at https://doi.org/ 10.1007/s10067-019-04455-y

Umut Kalyoncu

umut.kalyoncu@yahoo.com

1 Department of Internal Medicine, Division of Rheumatology, Hacettepe University Medical School, Sihhiye,

06100 Ankara, Turkey

2 Department of Internal Medicine, Department of Preventive Oncology, Hacettepe University Medical School, Ankara, Turkey 
Fig. 1 Algorithm for discrimination of adult onset Still's disease and other causes of fever of unknown origin. FUO: Fever of unknown origin, UNL: Upper normal limit (for ferritin: 336 ng/ml), PPV: Positive Predictive Value

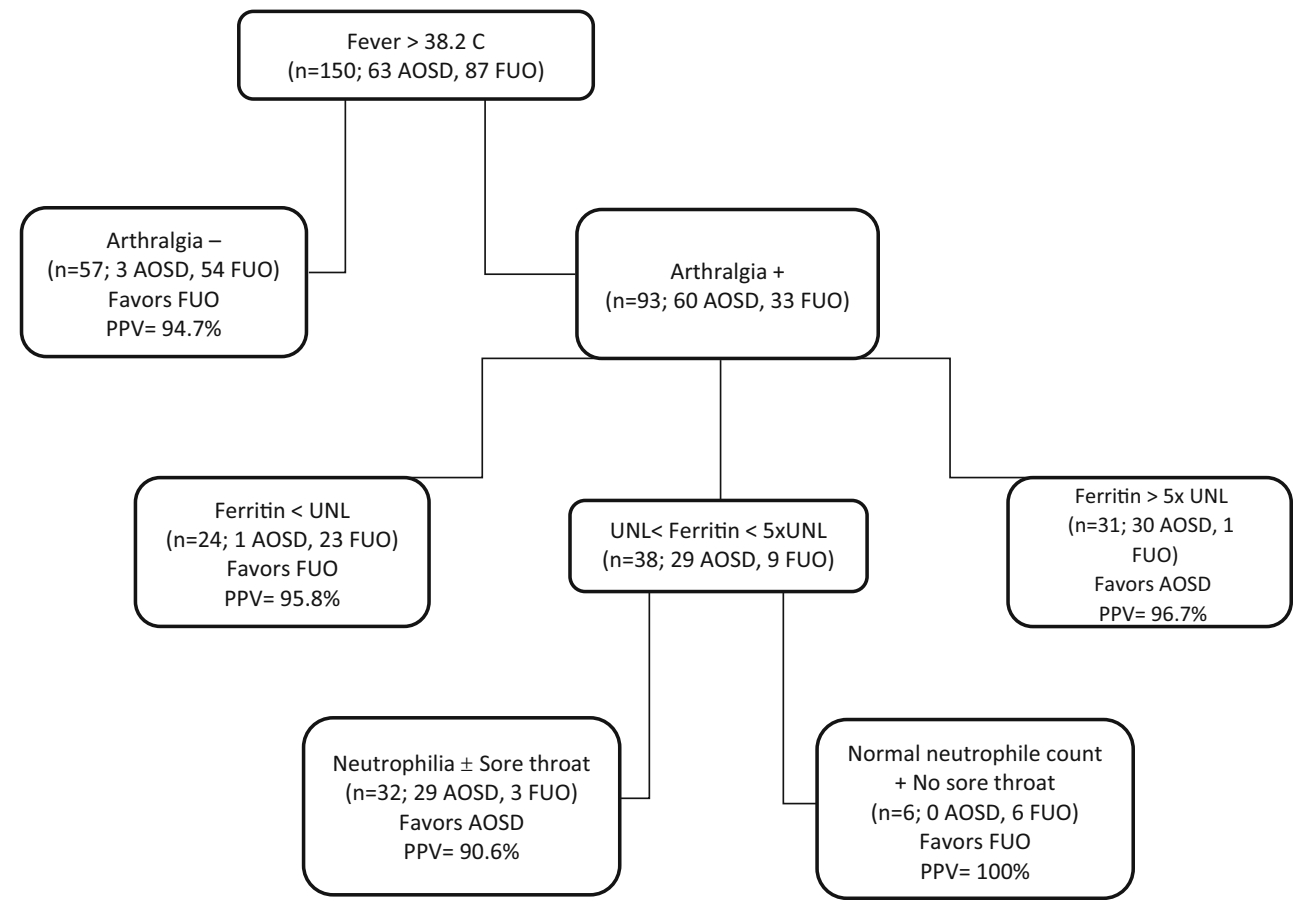

Publisher's note Springer Nature remains neutral with regard to jurisdictional claims in published maps and institutional affiliations. 